University of Nebraska - Lincoln

DigitalCommons@University of Nebraska - Lincoln

1998

Fungal Colonists of Maize Grain Conditioned at Constant Temperatures and Humidities

Donald T. Wicklow

USDA-ARS

David K. Weaver

USDA-ARS

James E. Throne

USDA-ARS, Manhattan, KS, james.throne@ars.usda.gov

Follow this and additional works at: https://digitalcommons.unl.edu/usdaarsfacpub

Wicklow, Donald T.; Weaver, David K.; and Throne, James E., "Fungal Colonists of Maize Grain Conditioned at Constant Temperatures and Humidities" (1998). Publications from USDA-ARS / UNL Faculty. 2064. https://digitalcommons.unl.edu/usdaarsfacpub/2064

This Article is brought to you for free and open access by the U.S. Department of Agriculture: Agricultural Research Service, Lincoln, Nebraska at DigitalCommons@University of Nebraska - Lincoln. It has been accepted for inclusion in Publications from USDA-ARS / UNL Faculty by an authorized administrator of DigitalCommons@University of Nebraska - Lincoln. 


\title{
Fungal Colonists of Maize Grain Conditioned at Constant Temperatures and Humidities
}

\author{
DONALD T. WICKLOW, ${ }^{1 *}$ DAVID K. WEAVER ${ }^{2} \uparrow$ and \\ JAMES E. THRONE ${ }^{3}$
}

\begin{abstract}
${ }^{\prime}$ Bioactive Agents Research, National Center for Agricultural Utilization Research, USDA, Agricultural Research Service, 1815 N University Street, Peoria, IL 61604, USA, ${ }^{2}$ Center for Medical, Agricultural and Veterinary Entomology, USDA, Agricultural Research Service, 1700 SW 23rd Drive, Gainesville, FL 32604, USA and ${ }^{3}$ Grain Marketing and Production Research Center, USDA, Agricultural

Research Service, 1515 College Avenue, Manhattan, KS 66502, USA
\end{abstract}

(Accepted 4 May 1998)

\begin{abstract}
Fungal colonization of shelled maize (Pioneer 3320) harvested from a field near Furman, South Carolina, in 1992 was determined after 348 and 751 days of continuous storage at each of seven temperatures $\left(10,15,20,25,30,35\right.$, or $\left.40^{\circ} \mathrm{C}\right)$ and four constant relative humidities, giving equilibrium grain moisture contents ranging from $9.4 \%$ to $17.5 \%$ m.c. in 28 grain conditioning environments. Twenty fungal species infected surface sterilized seeds and were recorded from these conditioned grain treatments, including species commonly found in preharvest maize [e.g. Acremonium zeae, Aspergillus flavus, Fusarium moniliforme (syn. F. verticillioides), Penicillium pinophilum (syn. P. funiculosum), etc.]. Eupenicillium cinnamopurpureum and Monascus ruber were recorded only from conditioned grain treatments. Eurotium chevalieri colonized $50-96 \%$ of the kernels from grain conditioning treatments with the highest moisture content for each incubation temperature. Grain samples with $>33 \%$ E. chevalieri infection had a decreased occurrence of $F$. moniliforme and $A$. zeae, and no kernels from these samples germinated. No fungi colonized more than $50 \%$ of the kernels conditioned at $30-40{ }^{\circ} \mathrm{C}$ and $9.4-14.2 \%$ m.c. The results of this study indicate that individual patterns of fungal colonization during grain conditioning were a function of the survival rates for preharvest fungal colonists and their potential replacement by $E$. chevalieri. Published by Elsevier Science Ltd
\end{abstract}

Key words - maize, storage, temperature, humidity, Eurotium, fungi

\section{INTRODUCTION}

The best known examples of fungal succession in stored grain bulks are associated with dramatic increases in grain moisture (damp grain pockets) and temperatures resulting from: (1) unsafe storage of high-moisture grain; (2) leaks in a storage structure; (3) moisture migration and condensation; (4) fungus-induced hot spots; and (5) insect-induced hot spots (Christensen and Kaufmann, 1969; Miller, 1995; Sauer et al., 1992; Sinha, 1992; Wicklow, 1995). Less atten-

Names are necessary to report factually on available data; however, the USDA neither guarantees nor warrants the standard of the product, and the use of the name by USDA implies no approval of the product to the exclusion of others that may also be suitable.

*Author for correspondence. Fax: + 309-681-6686.

$\uparrow$ Present address: Department of Entomology, Montana State University-Bozeman, 324 Leon Johnson Hall, P.O. Box 173020, Bozeman, MT 59717-3020, USA. 
tion has been given to interpretations of fungal colonization patterns in large storage bulks with consistent environmental conditions. At harvest, maize (Zea mays L.) kernels may be infected, colonized or contaminated with fungi representing different ecological groups including seed replacement pathogens, mildly parasitic colonists of the phylloplane, stem-rot and ear-rot pathogens, endophyte mutualists, saprotrophs and yeasts in dust from soil and/or crop residues (Wicklow, 1995). In storage, the growth and survival of these fungi is affected by tolerance to 'extreme conditions' (Lacey, 1980), grain moisture content, temperature, gas composition (Bottomley et al., 1950; Quasem and Christensen, 1958; Mislevic and Tuite, 1970; Marin et al., 1995), fungal species interactions (Wicklow et al., 1980, 1988; Wicklow, 1988), fungal interactions with granary insects and mites (Dharmaputra et al., 1994; Sinha, 1992; Barney et al., 1995), and active seed resistance to fungal infection (Moreno-Martinez and Christensen, 1971; Cantone et al., 1983; Yao and Tuite, 1989; Stroshine and Yang, 1990).

The present study examines patterns of fungal occurrence on undamaged maize grain conditioned for 348 and 751 days at each of seven temperatures $\left(10-40^{\circ} \mathrm{C}\right)$ and four relative humidities $(40-80 \%$ r.h.). These grain conditioning treatments were selected because they overlap environments in which 'storage molds' can grow and/or stored product arthropods (granary insects and mites) are reported to be active inhabitants (Arbogast and Mullen, 1988). The goal of this research was to understand how the grain storage environment impacts fungal colonization patterns in the absence of disturbance. Although it is known that fungi interact with arthropods, stored-product arthropods were necessarily excluded as confounding variables. In low-moisture environments, which are unfavorable for fungal growth, and in the absence of stored-product arthropods, the death of preharvest fungal colonists should result in fungal-free (uncolonized) grain.

\section{MATERIALS AND METHODS}

\section{Grain source and handling}

A commercial dent maize hybrid (Pioneer 3320) was grown to maturity in a field near Furman, SC in 1992. Grain was combine-harvested at $18-22 \%$ moisture content (m.c.) in late August, to limit preharvest field infestation by stored-product insects, and then dried at $40^{\circ} \mathrm{C}$ to $15 \%$ m.c. The grain was then cleaned with a sieve to remove broken kernels and foreign material (BCFM), delivered to the Savannah Laboratory in paper bags $(50 \mathrm{lbs})$, and immediately fumigated with phosphine ('Phostoxin,' Degesch, Laudenbach, Germany) at $1 \mathrm{~g} / 28.3 \mathrm{~m}^{3}$ for 4 days (at $20^{\circ} \mathrm{C}$; $50 \%$ r.h.) to kill any incipient insect infestation. The bags were then placed on wooden pallets in cold storage at $4.4^{\circ} \mathrm{C}$; with $20-30 \%$ r.h. The interval from grain harvest to cold storage did not exceed 14 days. A follow-up method of arthropod disinfestation included exposing the grain to $-20^{\circ} \mathrm{C}$ for 14 days immediately preceding moisture equilibration treatments.

\section{Storage environments}

Grain equilibration treatments were conducted using plastic boxes $(40 \times 27.5 \times 16 \mathrm{~cm})$ as humidity chambers that could be placed in temperature cabinets. Grain samples $(300 \mathrm{~g})$ were placed in individual acrylic tube containers $76 \mathrm{~mm}$ internal diameter $\times 71 \mathrm{~mm}$ high, with openings at the lid and base ends covered by nylon mesh (64 $\mu \mathrm{m}$ pore size). Two tube containers were placed in each humidity chamber. Constant humidities were produced and maintained at each of seven temperatures $\left(10,15,20,25,30,35\right.$ and $\left.40^{\circ} \mathrm{C}\right)$ using saturated salt solutions of $\mathrm{KCL}, \mathrm{NaCl}, \mathrm{NaBr}$, and $\mathrm{K}_{2} \mathrm{CO}_{3}$ (Winston and Bates, 1960; Greenspan, 1977). Approximately $600 \mathrm{ml}$ of each solution was poured into each box and a perforated false floor was placed in the bottom of each box to support the acrylic tubes containing individual grain samples above the salt solutions (Arthur et al., 1991). Grain moisture content was monitored in one of the containers, using a Motomco Model 919 automatic grain moisture tester (Dickey-John, Auburn, IL). The other container was not disturbed until the end of the study. Up to 7 wk incubation was required for grain samples to achieve equilibrium water balance at the lowest moisture contents. Equilibrium grain moisture contents (Table 1) were maintained by adding fresh saturated salt solution as needed. Response surface equations were fitted to the moisture content data using TableCurve 3D (Jandel Scientific, San Rafael, CA) with initial sorting specified by the magni- 
Table 1. Equilibrium moisture content (\%) wet weight basis of maize grain conditioned at constant humidities and temperatures using saturated salt solutions*

\begin{tabular}{|c|c|c|c|c|c|c|c|c|}
\hline \multirow{2}{*}{$\begin{array}{l}\text { Temperature } \\
\left({ }^{\circ} \mathrm{C}\right) \\
10\end{array}$} & \multicolumn{2}{|c|}{$\mathrm{KCl}$} & \multicolumn{2}{|c|}{$\mathrm{NaCl}$} & \multicolumn{2}{|c|}{$\mathrm{NaBr}$} & \multicolumn{2}{|c|}{$\mathrm{K}_{2} \mathrm{CO}_{3}$} \\
\hline & 17.5 & $(88.0)$ & 15.5 & $(76.5)$ & 13.8 & $(63.0)$ & 11.6 & $(47.0)$ \\
\hline 15 & 16.5 & $(86.5)$ & 15.4 & $(76.0)$ & 13.5 & $(61.0)$ & 11.3 & $(44.0)$ \\
\hline 20 & 16.4 & $(85.0)$ & 15.3 & $(76.0)$ & 13.3 & $(59.0)$ & 11.1 & $(44.0)$ \\
\hline 25 & 15.9 & $(85.0)$ & 14.9 & $(75.5)$ & 12.6 & (57.5) & 10.7 & $(43.0)$ \\
\hline 30 & 15.5 & (84.5) & 14.6 & (75.5) & 12.1 & $(56.0)$ & 10.4 & (43.5) \\
\hline 35 & 15.0 & (83.0) & 14.2 & (75.5) & 11.5 & (54.5) & 9.9 & (NL) \\
\hline 40 & 14.3 & $(82.0)$ & 13.7 & $(75.0)$ & 10.6 & $(53.0)$ & 9.4 & $(40.0)$ \\
\hline
\end{tabular}

*Relative humidity (r.h.) values in parentheses (Winston and Bates, 1960); NL = not listed.

tude of the regression F-statistic. Fitted biologically plausible equations were further evaluated for systematic trends in the residuals and for lack-of-fit (Draper and Smith, 1981). The disinfested grain bulk was subsampled for the following treatments: (1) immediate incubation in one of 28 grain conditioning environments for 751 days; (2) dry cold storage for 403 days followed by 348 days incubation in a parallel set of humidity chambers and temperature cabinets to reproduce each of the 28 grain conditioning environments; (3) dry cold storage for 751 days (control). Following the period of grain conditioning, all samples were placed under a hood and dried to $12-13 \%$ m.c. The dried samples were shipped to NCAUR, Peoria, IL, for fungal analyses which were performed within 3 months after the conditioning was terminated. During this interval, the grain samples were stored at $5^{\circ} \mathrm{C}$.

\section{Fungal evaluations}

Fungal colonization of grain incubated at different moisture and temperature combinations was determined on 50 randomly selected kernels (control sample $=100$ kernels). Kernels were surface-sterilized in a $1 \%$ sodium hypochlorite solution for $2 \mathrm{~min}$, then washed twice in sterile water. Five kernels were plated on each of 10 Petri dishes of malt extract agar $(30 \mathrm{~g}$ malt extract, $20 \mathrm{~g}$ agar, in 11 water), and incubated for 6 days at $25^{\circ} \mathrm{C}$. Fungi growing from the individual plated kernels were identified and their frequency (\%) of grain colonization was calculated. Isolations of representative fungal cultures were deposited with the ARS Culture Collection (NRRL), National Center for Agricultural Utilization Research, Peoria, IL 61604. A record was also made of the number of kernels that germinated on the agar.

\section{RESULTS AND DISCUSSION}

The moisture content of the equilibrated grain at different temperatures over various saturated salt solutions was quite stable over the duration of the experiment (Fig. 1). The abrupt change in moisture content at the beginning of the study is associated with the period of equilibration. Twenty fungal species were recorded from grain samples representing 28 conditioning treatments and incubation for 348 or 751 days (Table 2). Representative strains include: NRRL 25143 Acremonium zeae W. Gams and Sumn. (syn. Acremonium strictum); NRRL 25065 Aspergillus flavus Link; NRRL 25066 Aspergillus niger v. Tieghem; NRRL 25075 Eupenicillium cinnamopurpureum Scott and Stolk; NRRL 25068 Eurotium chevalieri Mangin; NRRL 25069 Monascus ruber v. Tieghem; NRRL 25071 Penicillium citrinum Thom; NRRL 25076 and NRRL 25074 Penicillium pinophilum Hedgcock (syn. P. funiculosum); NRRL 25144 Chaetomium globosum Kunze; NRRL 25147 and NRRL 25457 Fusarium verticillioides (Sacc.) Nirenb. (syn. F. moniliforme); NRRL 25152 Mycelia sterilia. Most of these fungi have been reported from preharvest maize, including commonly occurring species such as A. zeae, A. flavus, F. verticillioides, $P$. pinophilum, etc. In the present study, Eupenicillium cinnamopurpureum and Monascus ruber were recorded from maize grain incubated in several of the 28 grain conditioning environments.

Eurotium chevalieri was recorded from $20 \%$ of the 'control' grains sampled following 751 days cold storage. This fungus is known to invade corn in storage (Dharmaputra et al., 1994) and was not recorded from maize sampled at harvest throughout North Carolina (Hesseltine et al., 1981). Grain entering cold storage had about $15 \%$ m.c., sufficient moisture to support the 

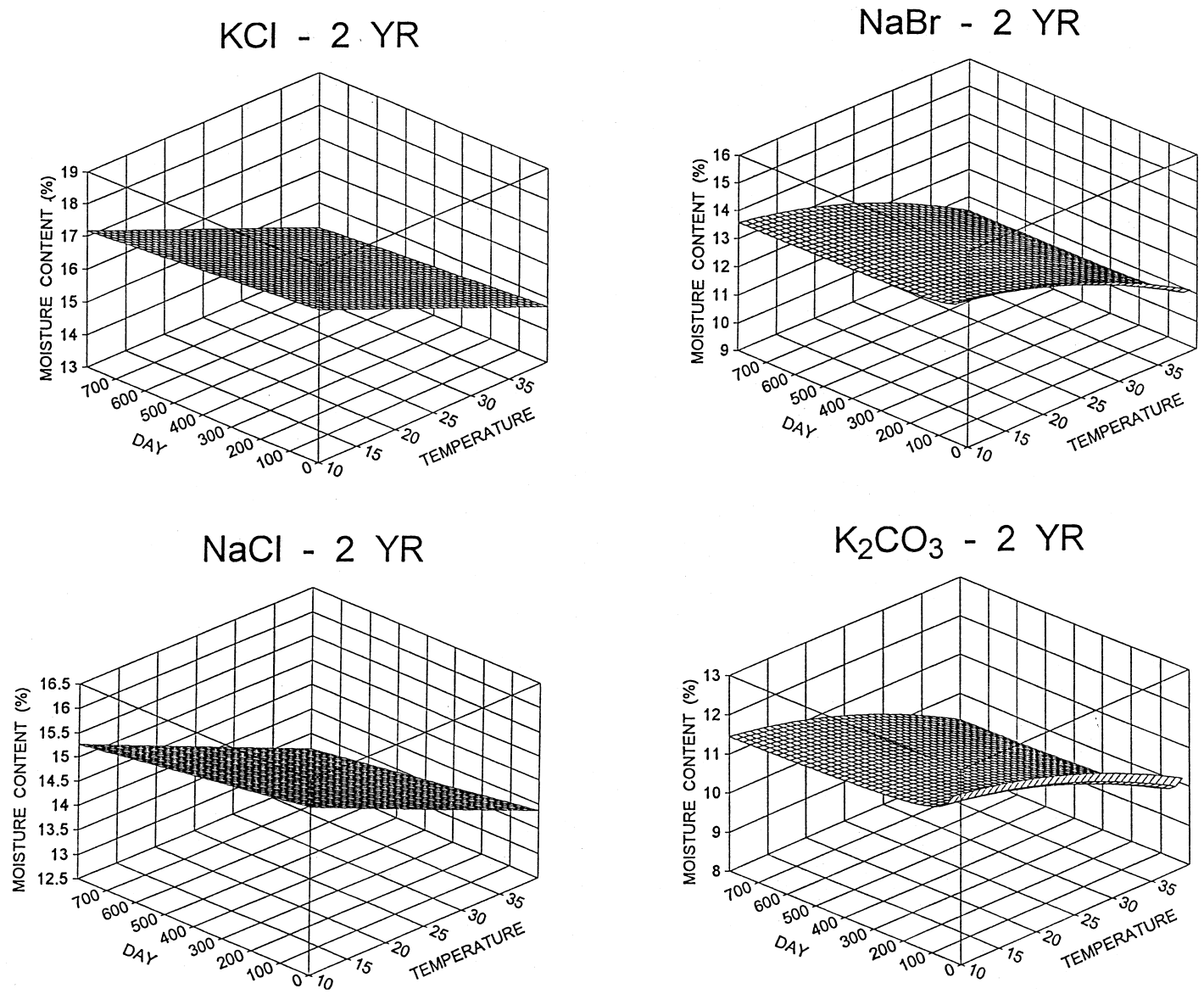

Fig. 1. Fitted response surface showing moisture content at specific temperatures for maize grain equilibrated over saturated solutions of potassium chloride, sodium chloride, sodium bromide, and potassium carbonate for 751 days.

growth of E. chevalieri and other members of the 'Aspergillus glaucus group' which can grow at a minimum temperature of $0-5^{\circ} \mathrm{C}$ (Christensen and Kaufmann, 1969; Kozakiewicz and Smith, 1994). Penicillium pinophilum also infected $20 \%$ of the kernels in cold storage while A. zeae infected only $6 \%$. However, $A$. zeae showed $20 \%$ kernel infection in several conditioning treatments where $P$. pinophilum infected $6 \%$ or fewer kernels (Table 2). Penicillium pinophilum suppresses growth of $A$. zeae when grown together on malt extract agar in Petri dish cultures incubated at $25^{\circ} \mathrm{C}$ (Wicklow et al., 1980).

Eurotium chevalieri colonized $47-96 \%$ of the kernels conditioned at the highest grain moisture content for each incubation temperature (Table 2). In these treatments there was a corresponding decrease in numbers of kernels showing $F$. moniliforme and $A$. zeae and the kernels did not germinate. Aspergillus flavus was also replaced by E. chevalieri in some of the treatments at $20^{\circ} \mathrm{C}$ and above. Wicklow (1995) suggests that Eurotium spp. may function as mycoparasites in species replacement, killing $F$. moniliforme and other fungal colonists of preharvest grain. Even so, $F$. moniliforme was recorded in significant numbers of kernels from grain samples in which E. chevalieri colonized a large majority of the kernels stored at 10 and $15^{\circ} \mathrm{C}$. Mycoparasitic behavior may be better expressed at temperatures favorable to the production of fungal cell wall degrading enzymes and/or antifungal metabolites. Aspergillus flavus also appears to have grown in storage, infecting larger numbers of kernels at $10^{\circ} \mathrm{C}$ with $17.5 \%$ m.c. Grain conditioned at $30-40{ }^{\circ} \mathrm{C}$ produced few germinated kernels, with no molds appearing on $50-100 \%$ of the kernels incubated at the lower humidities. Here the conditions do not favor survival of fungi infecting grain at harvest nor the growth of Eurotium spp. or other 'storage molds.' However, fungal metabolites may persist as chemical contaminants in these mold-free kernels. 
Fungal colonists of maize grain condtioned at constant temperatures and humidities

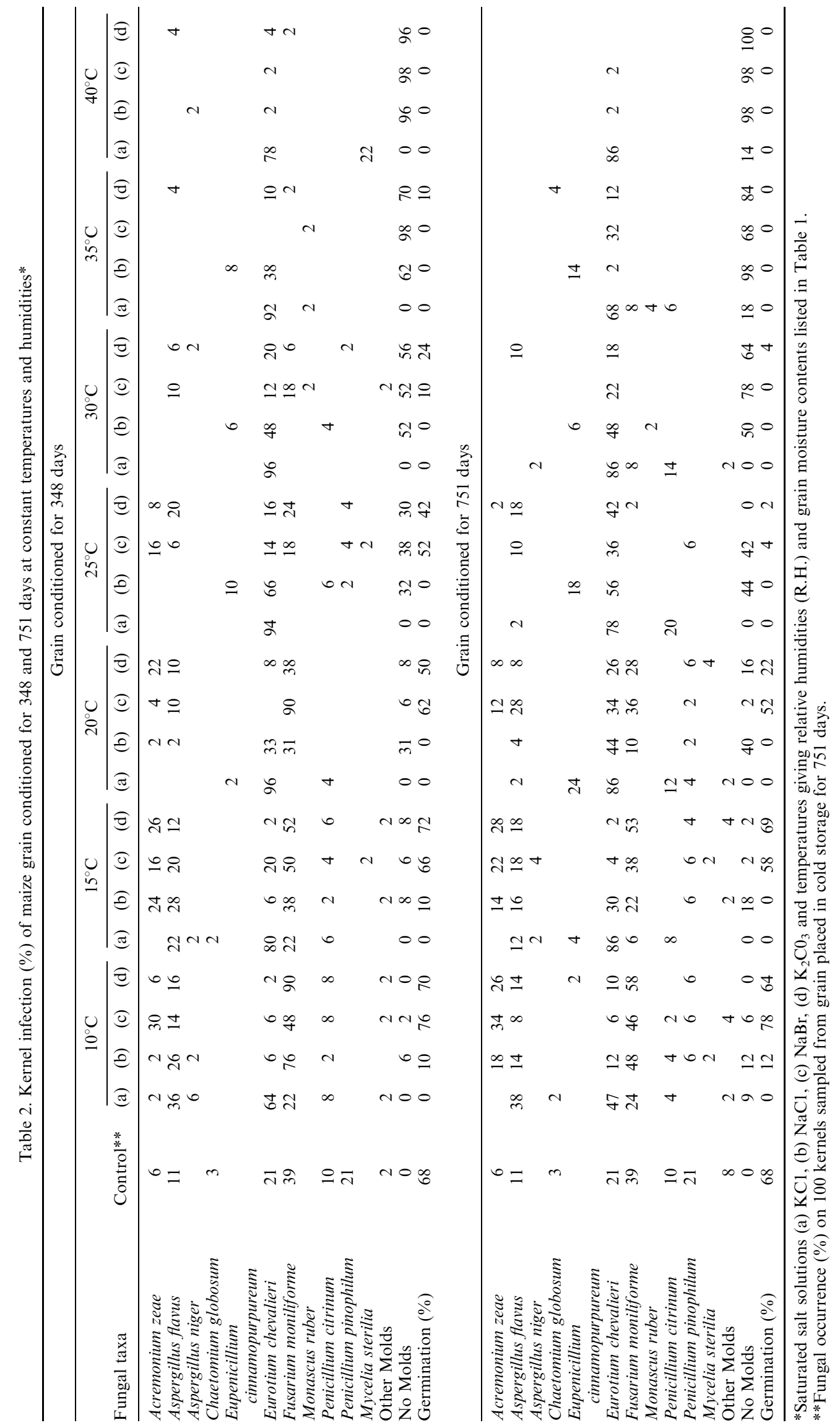


There were no major differences in fungal colonization pattern after 1 or 2 y of grain conditioning (Table 2). However, the numbers of kernels infected by a fungus increased significantly during the second year of incubation for E. chevalieri at $25^{\circ} \mathrm{C}$ and 12.6 or $10.7 \%$ m.c.; A. zeae at $10^{\circ} \mathrm{C}$ with 15.5 or $11.2 \%$ m.c., and Penicillium citrinum at $20-35^{\circ} \mathrm{C}$ with 16.4 or $15 \%$ m.c. Kernel germination losses also increased at $20^{\circ} \mathrm{C}$ with $11.1 \%$ m.c., and $30^{\circ} \mathrm{C}$ with 12.1 or $10.4 \%$ m.c. In some treatments, the occurrence of infected kernels decreased during the second year: $F$. moniliforme at $15^{\circ} \mathrm{C}$ with $16.5 \%$ m.c., $25^{\circ} \mathrm{C}$ with 12.6 or $10.7 \%$ m.c.; A. zeae at $25^{\circ} \mathrm{C}$ with 12.6 or $10.7 \%$ m.c.; $E$. chevalierii at $35^{\circ} \mathrm{C}$ with $14.2 \%$ m.c. Increased numbers of fungal-free kernels were recorded at $35^{\circ} \mathrm{C}$ with $15 \%$ m.c.; $40^{\circ} \mathrm{C}$ with $14.3 \%$ m.c. Christensen (1967) reported that corn stored for 2 y at $14.5 \%$ m.c. and $12{ }^{\circ} \mathrm{C}$ showed $46 \%$ kernel infection by $A$. glaucus and $15 \%$ kernel germination. For grain stored at $15.2 \%$ m.c. and $12{ }^{\circ} \mathrm{C}$, nearly all of the kernels were infected with $A$. glaucus group and no kernels germinated.

Storage molds do not usually penetrate and infect corn kernels before harvest (Quasem and Christensen, 1958). Eurotium spp. were rarely isolated from corn at harvest in Indiana (Tuite, 1961). At the same time, E. chevalieri, E. amstelodami, E. repens and E. ruber were isolated from shelled maize stored in bins throughout Iowa (Semeniuk et al., 1947). Koehler (1938) observed that A. glaucus group molds could always be isolated from maize kernels at $14.5-15.5 \%$ moisture, sometimes in the absence of other fungi. These molds slowly kill and discolor the germs at moisture contents near the lower limit for growth (14.0-14.5 m.c.) and cause "blue-eye" in corn stored at 14.5-15.0\% m.c. (Semeniuk et al., 1947; Christensen and Kaufmann, 1969). Tuite et al. (1985) wound-inoculated the germs of intact maize kernels with E. amstelodami, E. repens and $E$. ruber to show that damage provides necessary entry points for fungi to attack the germ. Eurotium chevalieri invaded undamaged, 'healthy dent kernels' incubated at $26^{\circ} \mathrm{C}$ and $98 \%$ r.h., producing cleistothecia in the space between the pericarp and the germ (Tsuruta et al., 1981).

In the absence of disturbance or introductions of fungal species by granary insects or mites, the patterns of fungal occurrence are a product of the ability of individual fungi to grow or survive in such environments, the outcome of interactions with other fungi, species replacement and extinction. The results of this study indicate that individual patterns of fungal colonization during grain conditioning were a function of the survival rates for pre-harvest fungal colonists and their potential replacement by E. chevalieri. Long-term mycological data are needed to evaluate the practical use of environmental controls (e.g. temperature, moisture content, $\mathrm{pH}$, decreased $\mathrm{O}_{2}$ and increased $\mathrm{CO}_{2}$ ) to maintain grain quality and in assessing economic cost (Tuite and Foster, 1979; Magan and Lacey, 1984). Grain-infesting insects or mites develop in molded grain, become contaminated with the spores of these storage fungi and carry the spores to clean grain (Griffiths et al., 1959; Sinha, 1992). These data on probable species present might also serve as a guide for interpreting insect behaviors (attractiveness vs. repellency) involving fungal volatiles (Sinha et al., 1988; Kaminski and Wasowicz, 1991) associated with naturally occurring pockets of molded grain in bulk storage, particularly with regard to movement and orientation of primary pests that can attack sound grain, as opposed to secondary pests that prefer damaged grain, and facultatively or truly fungivorous species.

\section{REFERENCES}

Arbogast R. T. and Mullen M. A. (1988) Insect succession in a stored-corn ecosystem in southeast Georgia. Annals of the Entomological Society of America 81, 899-912.

Arthur F. H., Throne J. E. and Simonaitis R. A. (1991) Chlorpyrifos-methyl degradation and biological efficacy toward maize weevils (Coleoptera: Curculionidae) on corn stored at four temperatures and three moisture contents. Journal of Economic Entomology 84, 1926-1932.

Barney R. J., Price B. D., Sedlacek J. D. and Siddiqui M. (1995) Fungal species composition and abundance on stored corn as influenced by several management practices and maize weevil (Coleoptera: Curculionidae). Crop Protection 14, $159-164$.

Bottomley R. A., Christensen C. M. and Geddes W. F. (1950) The influence of various temperatures, humidities, and oxygen concentrations on mold growth and biochemical changes in stored yellow corn. Grain Storage Studies IX. Cereal Chemistry 27, 271-296.

Cantone F. A., Tuite J., Bauman L. F. and Stroshine R. (1983) Genotype differences in reaction of stored corn kernels to attack by selected Aspergillus and Penicillium spp. Phytopathology 73, 1250-1255. 
Christensen C. M. (1967) Some changes in No. 2 corn stored two years at moisture contents of 14.5 and $15.2 \%$ and temperatures of $12^{\circ}, 20^{\circ}$, and $25^{\circ} \mathrm{C}$. Cereal Chemistry 44, 95-99.

Christensen C. M. and Kaufmann H. H. (1969) Grain Storage. The Role of Fungi in Quality Loss. University of Minnesota Press, Minneapolis, p. 153.

Dharmaputra O. S., Halid H., Khim S. and Khim K. S. (1994) The effect of Sitophilus zeamais on fungal infection, aflatoxin production, moisture content and damage to kernels of stored maize. In Stored Product Protection, Proceedings of the 6th International Working Conference on Stored Product Protection, Canberra, Australia. E. Highley, E. J. Wright, H. J. Banks and B. R. Champ (Ed.). CAB International, Wallingford, England, pp. 981-984.

Draper N. R. and Smith H. (1981) Applied regression analysis. 2nd edn. Wiley, New York.

Greenspan L. (1977) Humidity fixed points of binary saturated aqueous solutions. Journal of Research for National Bureau of Standards-A. Physics and Chemistry 81A, 89-96.

Griffiths D. A., Hodson A. C. and Christensen C. M. (1959) Grain storage fungi associated with mites. Journal of Economic Entomology 52, 514-518.

Hesseltine C. W., Rogers R. F. and Shotwell O. L. (1981) Aflatoxin and mold flora in North Carolina in 1977 corn crop. Mycologia 73, 216-228.

Kaminski E. and Wasowicz E. (1991) The usage of volatile compounds produced by moulds as indicators of grain deterioration. Developmental Food Science 26, 229-258.

Kozakiewicz Z. and Smith D. (1994) Physiology of Aspergillus In Aspergillus, Smith J. E. (Ed.). Biotechnology Handbooks Volume 7. Plenum Press, New York and London, pp. 23-40.

Koehler B. (1938) Fungus growth in shelled corn as affected by moisture. Journal of Agricultural Research 56, $291-307$.

Lacey J. (1980) Colonization of damp organic substrates and spontaneous heating. Microbial Growth and Survival in Extremes of Environment, Gould G. W. and Corry J. E. L. (Eds). Society of Applied Bacteriology Technical Series Volume 15. Academic Press, London and New York, pp. 53-70.

Magan N. and Lacey J. (1984) Effects of gas composition and water activity on growth of field and storage fungi and their interactions. Transactions of the British Mycological Society 82, 305-314.

Marin S., Sanchis V. and Magan N. (1995) Water activity, temperature and pH effects on growth of Fusarium moniliforme and Fusarium proliferatum isolates from maize. Canadian Journal of Microbiology 41, 1063-1070.

Miller J. D. (1995) Fungi and mycotoxins in grain: implications for stored product research. Journal of Stored Products Research 31, 1-16.

Mislevic P. B. and Tuite J. F. (1970) Temperature and relative humidity requirements of species of Penicillium spp. isolated from yellow dent corn. Mycologia 62, 74-88.

Moreno-Martinez E. and Christensen C. M. (1971) Differences among lines and varieties of maize in susceptibility to damage by storage fungi. Phytopathology 61, 1498-1500.

Qasem S. A. and Christensen C. M. (1958) Influence of moisture content, temperature, and time on the deterioration of stored corn by fungi. Phytopathology 48, 544-549.

Sauer D. B., Meronuck R. A. and Christensen C. M. (1992) Microflora. In Storage of Cereal Grains and Their Products, D. B. Sauer (Ed.). 4th Edition. American Association of Cereal Chemists, St. Paul, MN, pp. 313-340.

Semeniuk G., Nagel C. M. and Gilman J. C. (1947) Observations on mold development and on deterioration in stored yellow dent shelled corn. Iowa State Agricultural Experiment Station Research Bulletin No. 349, $255-284$.

Sinha R. N. (1992) The fungal community in the stored grain ecosystem. In The Fungal Community-Its Organization and Role in the Ecosystem, G. C. Carroll and D. T. Wicklow (Ed.). Second Edition. Marcel Dekker, New York, Basel and Hong Kong. pp. 797-815.

Sinha R. N., Tuma D., Abramson D. and Muir W. E. (1988) Fungal volatiles associated with moldy grain in ventilated and non-ventilated bin-stored wheat. Mycopathologia 101, 53-60.

Stroshine R. L. and Yang X. (1990) Effects of hybrid and grain damage on estimated dry matter loss for high-moisture shelled corn. Transactions of the American Society of Agricultural Engineers 33, 1291-1298.

Tsuruta O., Gohara S. and Saito M. (1981) Scanning electron microscopic observations of a fungi invasion of corn kernels. Transactions of the Mycological Society of Japan 22, 121-126.

Tuite J. (1961) Fungi isolated from unstored corn seed in Indiana in 1956-1958. Plant Disease Reporter 45, $212-215$.

Tuite J. and Foster G. H. (1979) Control of storage diseases of grain. Annual Review of Phytopathology 17, $343-366$.

Tuite J., Koh-Knox C., Stroshine R., Cantone F. A. and Bauman L. F. (1985) Effect of physical damage to corn kernels on the development of Penicillium species and Aspergillus glaucus in storage. Phytopathology 75, 1137-1140.

Wicklow D. T. (1995) The Mycology of Stored Grain: An Ecological Perspective. In Stored Grain Ecosystems. D. S. Jayas, N. D. G. White and W. E. Muir (Ed.). Marcel Dekker, New York, Basel and Hong Kong, pp. 197-249.

Wicklow D. T. (1988) Patterns of fungal association within maize kernels harvested in North Carolina. Plant Disease 72 , $113-115$.

Wicklow D. T., Hesseltine C. W., Shotwell O. L. and Adams G. L. (1980) Interference competition and aflatoxin levels in corn. Phytopathology 70, 761-764.

Wicklow D. T., Horn B. W., Shotwell O. L., Hesseltine C. W. and Caldwell R. W. (1988) Fungal interference with Aspergillus flavus infection and aflatoxin contamination of maize grown in a controlled environment. Phytopathology 78, 68-74.

Winston P. W. and Bates D. H. (1960) Saturated solutions for the control of humidity in biological research. Ecology 41, 232-237.

Yao B. and Tuite J. (1989) The effects of heat treatment and inoculum concentration on growth and sporulation of Penicillium spp. on corn genotypes in storage. Phytopathology 79, 1101-1104. 